\title{
Review and recommendations on management of refractory raised intracranial pressure in aneurysmal subarachnoid hemorrhage
}

This article was published in the following Dove Press journal:

Vascular Health and Risk Management

10 July 2013

Number of times this article has been viewed

\author{
Calvin Hoi Kwan Mak \\ Yeow Yuen Lu \\ George Kwok Chu Wong \\ Department of Surgery, Prince of \\ Wales Hospital, Shatin, Hong Kong
}

Correspondence: George Kwok Chu Wong

Department of Surgery, 4/F, Clinical

Science Building, Prince of Wales Hospital, 30-32 Ngan Shing Street, Shatin, NT, Hong Kong

Tel +85226322624

Fax +852 26377974

Email georgewong@surgery.cuhk.edu.hk

\begin{abstract}
Intracranial hypertension is commonly encountered in poor-grade aneurysmal subarachnoid hemorrhage patients. Refractory raised intracranial pressure is associated with poor prognosis. The management of raised intracranial pressure is commonly referenced to experiences in traumatic brain injury. However, pathophysiologically, aneurysmal subarachnoid hemorrhage is different from traumatic brain injury. Currently, there is a paucity of consensus on the management of refractory raised intracranial pressure in spontaneous subarachnoid hemorrhage. We discuss in this paper the role of hyperosmolar agents, hypothermia, barbiturates, and decompressive craniectomy in managing raised intracranial pressure refractory to first-line treatment, in which preliminary data supported the use of hypertonic saline and secondary decompressive craniectomy. Future clinical trials should be carried out to delineate better their roles in management of raised intracranial pressure in aneurysmal subarachnoid hemorrhage patients.
\end{abstract}

Keywords: aneurysm, intracranial pressure, intracranial hypertension, subarachnoid hemorrhage

\section{Introduction}

Aneurysmal subarachnoid hemorrhage (aSAH) is associated with significant morbidity and mortality. ${ }^{1}$ An important prognosticator is the admission neurological status, which includes the Hunt and Hess grade ${ }^{2}$ and the World Federation of Neurosurgical Societies (WFNS) grade. ${ }^{3}$ Raised intracranial pressure is associated with poor-grade aSAH, ${ }^{4}$ which was thought to have a dismal outcome irrespective of aggressive management in the past. With advances in cerebral aneurysm treatment and neurointensive care, half of the poor-grade aSAH patients can attain a favorable outcome if intracranial pressure can be controlled to reduce secondary brain injury.,

Management of raised intracranial pressure (ICP), or intracranial hypertension, has been extensively investigated and translated into clinical practice in traumatic brain injury (TBI). However, there is lack of consensus on the management of raised ICP in aSAH, especially when refractory to first-line treatment. ${ }^{7-11}$ High ICP in aSAH is associated with poor outcome. ${ }^{12,13}$ Ryttlefors et $\mathrm{al}^{14}$ and Heuer et $\mathrm{al}^{15}$ both observed that in aSAH patients, refractory raised ICP is associated with unfavorable neurological outcome. The authors suggested that a better understanding and more aggressive approach in treating raised ICP may improve prognosis.

Standard therapies in treating high ICP in aSAH are frequently adopted from experiences from TBI, including optimizing cerebral venous outflow, controlled 
hyperventilation, sedation with analgesia, cerebrospinal fluid diversion, and surgical removal of space-occupying intracranial hematoma. ${ }^{16,17}$ Second-tier treatments include mannitol, hypertonic saline, therapeutic hypothermia, barbiturate coma, and decompressive craniectomy. We aimed to review the literature about the effectiveness of these "salvage therapies" for refractory raised ICP in aSAH.

\section{Pathophysiology of raised intracranial pressure in aSAH}

Intracranial hypertension after aSAH can be due to cerebral edema, intracranial hematoma, hydrocephalus, intraventricular hemorrhage, early brain injury, aneurysm rerupture, aneurysm treatment, or delayed cerebral ischemia. ${ }^{15}$

Cerebral infarct can take place as a consequence following vasospasm or as a complication after endovascular coiling or microsurgical clipping of ruptured aneurysms, and could contribute to raised ICP. Cerebral vasospasm usually peaks 4-10 days after initial hemorrhage, and can lead to delayed global cerebral edema in $20 \%$ of patients and hence elevated ICP. ${ }^{18,19}$ The resulting vicious cycle of raised ICP leads to insufficient cerebral perfusion pressure, contributes significantly to morbidity and mortality in patients with aSAH. ${ }^{20,21}$ Delayed cerebral infarction can also lead to similar disastrous results. ${ }^{22}$

Nagel et al studied the effect of intracranial hypertension following aSAH with cerebral microdialysis. ${ }^{23}$ In patients with aSAH and intracranial hypertension, cerebral metabolic levels were severely deranged compared to those in patients with normal ICP, and were reflected in high levels of markers of "cerebral crisis." Of these, both the excitotoxic neurotransmitter glutamate and membrane-degradation marker glycerol in cerebral dialysate further deteriorated 5 days after ictus, possibly reflecting development of secondary brain damage. The authors also found that ICP more than $20 \mathrm{mmHg}$ was a strong predictor of death and associated with unfavorable neurological outcome.

In TBI, elevated ICP has consistently been associated with poor outcome. Marmarou et $\mathrm{al}^{24}$ observed that outcome after TBI was significantly worse among patients with ICP greater than $20 \mathrm{mmHg}$. This was confirmed in a recent systematic review on TBI, where mortality reaches $55.6 \%$ for those with ICP $>40 \mathrm{mmHg}$, and refractory intracranial hypertension in TBI patients had an 88-time-higher chance of mortality. ${ }^{25}$ This ICP cutoff value from TBI treatment is also frequently used in managing aSAH. In contrast to TBI, decompensation of ICP in aSAH patients could occur earlier with the appearance of delayed cerebral infarction. ${ }^{26}$ Cerebral edema and/or intraparenchymal hematoma in aSAH can also lead to increased ICP, and is a significant poor prognostic factor. ${ }^{27}$

\section{Hyperosmolar agents}

Hyperosmolar agents such as mannitol and hypertonic saline are commonly used empirically for ICP control. They induce an immediate reduction in ICP through changes in bloodfluid dynamics or rheology. Their osmotic properties then produce a reduction in brain-water content and a reduction in brain volume, in the presence of an intact blood-brain barrier, which in return reduces ICP within a rigid skull (the Monro-Kellie hypothesis). ${ }^{28}$

For TBI patients, guidelines from the Brain Trauma Foundation in 2007, in cooperation with three neurosurgical societies, suggested level II evidence for the effectiveness of mannitol at doses of $0.25-1 \mathrm{~g} / \mathrm{kg}$ of body weight to reduce ICP. ${ }^{29}$ However mannitol is associated with systemic hypotension due to secondary effects from decreasing peripheral vascular resistance. Prolonged administration can result in diuresis and hypovolemia, bearing risk of further reducing perfusion to the brain by lowering the blood pressure. ${ }^{30}$ Hypovolemia and hypotension are at odds with the hypervolemic and hypertensive treatment of vasospasm. ${ }^{31}$ On the other hand, hypertonic saline improves rheology and exerts a positive inotropic effect, in addition to hemodilution and hyperosmolarity. The hypertensive, hypervolemic, and hemodilution effect is similar to triple- $\mathrm{H}$ therapy for prevention and treatment of vasospasm. ${ }^{30-37}$ The Brain Trauma Foundation guidelines state that no direction can be given regarding the use of hypertonic saline or the interval of administration of any hyperosmolar agent, yet suggested hypertonic saline may be superior to mannitol, with better hemodynamic parameters, which can be of benefit in aSAH. Case series have shown hypertonic saline is also effective in lowering ICP in SAH that was refractory to medical treatment. ${ }^{34}$ There is no clinical trial data looking particularly at the effect of mannitol in aSAH. Several trials have examined the safety and efficacy of using hypertonic saline in aSAH (Table 1).

A retrospective study by Suarez et $\mathrm{al}^{35}$ found no complication with hypertonic saline infusion. Tseng et $\mathrm{al}^{32}$ demonstrated that hypertonic saline can be effective in ICP reduction in poor-grade aSAH. Sixteen of the 17 treatment episodes showed improved perfusion to ischemic areas, with increased global cerebral perfusion pressure in all cases. Two prospective studies published in 2007 and 2010 confirmed the radiological improvement in cerebral perfusion and respectively clinical improvement. The degree of cerebral blood flow 
Table I Summary of clinical trials of hypertonic saline in aneurysmal subarachnoid hemorrhage

\begin{tabular}{|c|c|c|c|c|c|}
\hline Study & Study type & $\begin{array}{l}\text { Number of } \\
\text { treatments }\end{array}$ & Dose & ICP reduction & Other outcome \\
\hline Suarez et $\mathrm{al}^{35}$ & Retrospective & 29 & $\begin{array}{l}\text { Continuous 3\% } \\
\mathrm{NaCl} \text { acetate }\end{array}$ & Not studied & $\begin{array}{l}\text { No effect on CBF } \\
\text { velocities }\end{array}$ \\
\hline Tseng et $\mathrm{a}^{32}$ & Retrospective & 17 & $23.4 \% \mathrm{NaCl}$ boluses & $74.7 \%$ at 60 minutes & $\begin{array}{l}\text { Improvement of perfusion } \\
\text { defects on xenon CT scans }\end{array}$ \\
\hline Bentsen et $\mathrm{al}^{36}$ & $\begin{array}{l}\text { Prospective randomized, } \\
\text { single-blind, } \\
\text { placebo-controlled }\end{array}$ & 22 & $\begin{array}{l}7.2 \% \mathrm{NaCl} \text { in } 6 \% \\
\text { hydroxyethyl } \\
\text { starch boluses }\end{array}$ & $\begin{array}{l}37 \% \text { compared } \\
\text { with control at } \\
64 \text { minutes }\end{array}$ & $\begin{array}{l}\text { Beneficial hemodynamic } \\
\text { effects with increased } \\
\text { cardiac index }\end{array}$ \\
\hline Tseng et $\mathrm{a}^{33}$ & Prospective & 35 & $23.5 \% \mathrm{NaCl}$ boluses & $93.1 \%$ at 60 minutes & $\begin{array}{l}\text { Improvement in CBF } \\
\text { on xenon CT scans, and } \\
\text { associated with improved } \\
\text { outcome at discharge }\end{array}$ \\
\hline Al-Rawi et al ${ }^{37}$ & Prospective & 44 & $23.5 \% \mathrm{NaCl}$ boluses & $67.4 \%$ at 30 minutes & $\begin{array}{l}\text { Improvement in cerebral } \\
\text { oxygenation on xenon } \\
\text { CT scans and favorable } \\
\text { outcome at } 12 \text { months }\end{array}$ \\
\hline
\end{tabular}

Abbreviations: ICP, intracranial pressure; $\mathrm{CBF}$, cerebral blood flow; $\mathrm{CT}$, computed tomography; $\mathrm{NaCl}$, sodium chloride.

(CBF) enhancement following hypertonic saline therapy was associated with favorable outcome (modified Rankin scale score of 1-3) upon discharge. ${ }^{33}$ These investigators later also found that administering hypertonic saline to patients with poor-grade aSAH improved $\mathrm{CBF}$ and cerebral oxygenation, and was associated with favorable outcome at 12 months after intervention. ${ }^{37}$ The only available pilot randomized trial, by Bentsen et al, ${ }^{36}$ showed that hypertonic saline improved ICP control and increased cardiac index in poor-grade aSAH patients. However, it was only single-blinded, and consisted of only eleven patients each in the hypertonic saline group and normal saline group.

Most of these studies did not take into account the refractoriness of raised ICP. Pathophysiologically, the demonstrated effects of hypertonic saline in lowering ICP and improving cerebral perfusion could potentially improve clinical outcome in refractory ICP in aSAH.

\section{Recommendation}

While mannitol and hypertonic saline have been shown to reduce ICP in TBI patients, such effect on clinical outcome is lacking in aSAH. Hypertonic saline may improve CBF and outcome. Further randomized placebo-controlled clinical trials should be conducted for hypertonic saline in aSAH patients based on these encouraging initial data.

\section{Hypothermia}

Therapeutic hypothermia is generally defined as a body temperature in the range of about $33^{\circ} \mathrm{C}-35^{\circ} \mathrm{C} . .^{38,39}$ Peterson et al analyzed 1339 TBI patients who received hypothermia as treatment in eight randomized controlled trials, and found that reduction in risk of mortality was greatest and favorable neurologic outcomes much more common when hypothermia was maintained for more than 2 days. ${ }^{40}$ Prophylactic hypothermia is associated with better outcome when compared with normothermic controls in TBI patients, according to the guidelines by the Brain Trauma Foundation. ${ }^{41}$ On the other hand, hypothermia is associated with electrolyte imbalance and significant risks of infection, including pneumonia, which can further increase when combined with barbiturates. ${ }^{40}$ Although mild hypothermia in rat $\mathrm{SAH}$ models has been shown to reduce brain edema, ${ }^{42}$ clinical benefits remained unclear in ICP control and outcome in aSAH.

Zhao et $\mathrm{al}^{38}$ and $\mathrm{Li}$ et $\mathrm{al}^{43}$ conducted systemic reviews on intraoperative hypothermia for microsurgical clipping of ruptured cerebral aneurysms in aSAH patients, which included the same three well-conducted randomized controlled trials with a total of 1158 participants. ${ }^{44-46} \mathrm{Li}$ et al concluded that this treatment did not show statistically significant benefit in reduction in mortality and clinical outcome, ${ }^{43}$ which concurred with the conclusions of Zhao et al that there was no statistical difference in clinical outcome for intraoperative hypothermia over normothermia. ${ }^{38}$ Both groups concluded there was no difference in perioperative, intraoperative, and postoperative adverse events in between the mild-hypothermia and normothermia groups.

There are a few clinical studies on the effect of systemic hypothermia in aSAH. Inamasu and Ichikizaki ${ }^{47}$ treated eleven patients with poor-grade aSAH and intracranial hypertension refractory to mannitol with hypothermia for 3 days. Although ICP control was able to be achieved 
in nine patients, eight patients died and three patients were severely disabled or in a persistent vegetative state.

A cohort of 100 consecutive patients with refractory intracranial hypertension following aSAH were treated with prolonged mild hypothermia for a mean duration of 7 days, and $35.6 \%$ achieved good outcome at 1 year. ${ }^{48}$ However, 93\% of the participants suffered from at least one clinically significant side effect, including electrolyte disorders, pneumonia, thrombocytopenia, and septic shock syndrome. Six patients died as a result of respiratory or multiorgan failure.

\section{Recommendation}

Reports from the literature suggested that systemic hypothermia was feasible for aSAH patients. However, there is no evidence that systemic hypothermia for refractory raised ICP can improve clinical outcome in aSAH patients.

\section{Barbiturate coma}

Barbiturates primarily exert their sedative and anesthetic effects by potentiating the action of gamma-aminobutyric acid (GABA) at the $\mathrm{GABA}_{\mathrm{A}}$ receptor. Barbituates suppress cerebral metabolism, causing reduction in the cerebral metabolic rate of oxygen consumption, reduction in $\mathrm{CBF}$, and decrease in cerebral blood volume and ICP. ${ }^{49}$ Both pentobarbitone and thiopentone can significantly reduce acute and chronic intracranial hypertension. ${ }^{50}$ Earlier case series suggested patients with refractory vasospasm complicating aSAH can have good recovery with barbiturate coma compared with historical controls. ${ }^{51,52}$

However, barbiturates are associated with adverse effects, including cardiorespiratory depression, a prolonged duration of postinfusion clinical unresponsiveness, impaired white cell function, hypokalemia, and hepatic and renal dysfunction. ${ }^{49}$ It was demonstrated that blood-pressure reduction is significant, ${ }^{53}$ and might therefore adversely affect cerebral perfusion pressure and outcome. A systemic review in 2012 including seven randomized controlled trials and 341 patients concluded that there was no evidence that barbiturate therapy improves outcome in TBI patients. ${ }^{54}$ Hypotension was observed in $25 \%$ of patients, ${ }^{55,56}$ which is antagonistic to the beneficial effects of ICP control. The hypotensive effect could even be harmful in aSAH, exacerbating vasospasm and delayed cerebral infarction. One should be reminded that induced hypertension, associated with higher $\mathrm{CBF}$, can reverse ischemic neurological deficits in approximately two-thirds of patients with vasospasm after aSAH. ${ }^{57}$

\section{Recommendation}

With the lack of evidence to support an overall beneficial effect of barbituate coma in patients with aSAH and the known side-effects, barbiturate coma should not be routinely administered for aSAH patients with refractory raised $\mathrm{ICP}$.

\section{Decompressive craniectomy}

Decompressive surgery for refractory intracranial hypertension is directed towards improving cerebral perfusion, preventing ischemic damage, and avoiding brain herniation. The rationale for decompressive surgery is based on the MonroKellie doctrine. Accordingly, intracranial volume should remain constant, and volumetric compensations should be achieved by shifts in cerebrospinal fluid, $\mathrm{CBF}$, or brain herniation. ${ }^{58}$ Decompressive craniectomy removes part of the rigid skull so the intracranial volume can expand through the skull and dural defect, and hence ICP can be lowered. Its effectiveness in reducing ICP in severe TBI was demonstrated in different studies, ${ }^{59,60}$ and is increasingly utilized for refractory ICP control. Although Sahuquillo and Arikan ${ }^{58}$ did a systematic review and failed to find a significant association with better neurological outcome for decompressive craniectomy in TBI patients, favorable outcomes may be expected in selected patients with decompressive craniectomy for salvaging high ICP after maximizing medical treatment. ${ }^{58}$ It is thus reasonable to believe the procedure would play a similar role in ICP control in aSAH, and hence improve clinical outcome. Similar to TBI, decompressive craniectomy for aSAH can also be performed as primary prophylaxis apart from secondary salvage purposes. Prophylactic decompression or primary decompressive craniectomy is defined as any surgical decompression performed in patients undergoing craniectomy primarily for the evacuation of any type of intradural lesion. The aim of prophylactic craniectomy is not to control refractory ICP, but to avoid expected postsurgical increase in ICP. ${ }^{58}$

Fisher and Ojemann suggested that rapid increase in ICP can result in a "feed-forward" cycle of brain injury, causing a vicious cycle of cerebral anoxia and edema. ${ }^{61}$ Decompressive craniectomy helped in breaking this cycle. Jaeger et al reported that following decompressive craniectomy for medically intractable ICP elevation in three patients with diffuse cerebral edema secondary to aneurysmal SAH, cerebral tissue oxygenation improved. ${ }^{62}$ Similar improvement in cerebral tissue oxygenation was also reported by Stiefel et al. ${ }^{63}$ It was also found that neurogenic hypotension due to brain-stem compression was relieved after decompressive craniectomy, 
possibly due to a restoration of normal basal sympathetic vascular tone. ${ }^{64}$

The presence of intracranial hematoma in aSAH was associated with a worse prognosis. ${ }^{65}$ Buschmann et al treated 38 patients with aSAH by using decompressive craniectomy for intractable raised ICP and found $52.6 \%$ favorable outcomes (Glasgow Outcome Scale 4-5) after 12 months. ${ }^{66}$ Among those in whom secondary decompressive craniectomy was performed, $72.7 \%$ patients attained favorable outcome in those without infarct, whereas only $16.7 \%$ had a favorable outcome in the group with delayed infarct and refractory intracranial hypertension. Similarly, among the 79 aSAH patients where Güresir et al performed 16 decompressive craniectomy, for raised ICP secondary to brain edema without infarction or rebleeding. ${ }^{67}$ At 6 months, $37.5 \%$ had a good outcome (modified Rankin Scale 1-3), compared to an overall $26.6 \%$ in all craniectomy patients. This suggested that patients with progressive cerebral edema without radiological signs of infarction may benefit most from secondary decompressive craniectomy in aSAH.

Schirmer et al found that for intractable intracranial hypertension in aSAH, the long-term outcome was better for patients who underwent secondary decompressive craniectomy within the first 48 hours of aSAH. ${ }^{68}$ With its potential role in improving outcome, prophylactic decompressive craniectomy was reported in eight patients with poor-grade aSAH with large sylvian hematomas. ${ }^{69}$ Five out of the eight patients enjoyed excellent or good outcome at 1 year, suggesting the potential beneficial effect on rapid control of ICP may translate into good outcome. Another retrospective study also had similar findings: prophylactic decompressive craniectomy in patients led to more than half of them enjoying a favorable outcome among those presenting with WFNS grade IV aSAH together with large intracerebral or sylvian hematomas. ${ }^{70}$

Complications of decompressive craniectomy can include infection, development of subdural hygroma, and syndrome of the trephined in the later phase of recovery, characterized by new cognitive, neurological, or psychological deficits. ${ }^{71-74}$ Decompressive hemicraniectomy was associated with postoperative hydrocephalus, and it was postulated that the cerebrospinal fluid-flow dynamic was disturbed after part of the skull vault was removed. ${ }^{75,76}$

\section{Recommendation}

Although there is a lack of randomized controlled trials on the efficacy of decompressive craniectomy, it could be considered for refractory raised ICP in aSAH patients when medical treatment has been exhausted, as preliminary evidence suggests that decompressive craniectomy can reduce mortality and improve clinical outcome. Further clinical trials are required to investigate the timing, indications, and the balance between the beneficial and detrimental effects.

\section{Conclusion}

Raised ICP refractory to standard treatment in aSAH can lead to poor outcome and mortality. Preliminary data supported the use of hypertonic saline and secondary decompressive craniectomy, but further randomized trials should be conducted.

\section{Disclosure}

The authors report no conflicts of interest in this work.

\section{References}

1. van Gijn J, Kerr RS, Rinkel GJE. Subarachnoid haemorrhage. Lancet. 2007;369(9558):306-318.

2. Hunt WE, Hess RM. Surgical risk as related to time of intervention in the repair of intracranial aneurysms. J Neurosurg. 1968;28(1):14-20.

3. [No authors listed]. Report of World Federation of Neurological Surgeons Committee on a Universal Subarachnoid Hemorrhage Grading Scale. J Neurosurg. 1988;68(6):985-986.

4. Bailes JE, Spetzler RF, Hadley MN, Baldwin HZ. Management morbidity and mortality of poor-grade aneurysm patients. JNeurosurg. 1990;72(4):559-566.

5. Le Roux PD, Elliott JP, Newell DW, Grady MS, Winn HR. Predicting outcome in poor-grade patients with subarachnoid hemorrhage: a retrospective review of 159 aggressively managed cases. J Neurosurg. 1996;85(1):39-49.

6. Wartenberg KE. Critical care of poor-grade subarachnoid hemorrhage. Curr Opin Crit Care. 2011;17(2):85-93.

7. Bederson JB, Connolly ES Jr, Batjer HH, et al. Guidelines for the management of aneurysmal subarachnoid hemorrhage: a statement for healthcare professionals from a special writing group of the Stroke Council, American Heart Association. Stroke. 2009;40(3):994-1025.

8. Diringer MN, Bleck TP, Claude Hemphill J 3rd, et al. Critical care management of patients following aneurysmal subarachnoid hemorrhage: recommendations from the Neurocritical Care Society's Multidisciplinary Consensus Conference. Neurocrit Care. 2011;15(2):211-240.

9. Kimball MM, Velat GJ, Hoh BL. Critical care guidelines on the endovascular management of cerebral vasospasm. Neurocrit Care. 2011;15(2):336-341.

10. Shinohara Y, Yanagihara T, Abe K, et al. IV. Subarachnoid hemorrhage. J Stroke Cerebrovasc Dis. 2011;20(Suppl 4):S100-S115.

11. Connolly ES Jr, Rabinstein AA, Carhuapoma JR, et al. Guidelines for the management of aneurysmal subarachnoid hemorrhage: a guideline for healthcare professionals from the American Heart Association/ American Stroke Association. Stroke. 2012;43(6):1711-1737.

12. Soehle M, Chatfield DA, Czosnyka M, Kirkpatrick PJ. Predictive value of initial clinical status, intracranial pressure and transcranial Doppler pulsatility after subarachnoid haemorrhage. Acta Neurochir (Wien). 2007;149(6):575-583.

13. Yoshimoto Y, Wakai S, Satoh A, Hirose Y. Intraparenchymal and intrasylvian haematomas secondary to ruptured middle cerebral artery aneurysms: prognostic factors and therapeutic considerations. $\mathrm{Br} J$ Neurosurg. 1999;13(1):18-24.

14. Ryttlefors M, Howells T, Nilsson P, Ronne-Engstrom E, Enblad P. Secondary insults in subarachnoid hemorrhage: occurrence and impact on outcome and clinical deterioration. Neurosurgery. 2007;61(4):704-714; discussion 714-705. 
15. Heuer GG, Smith MJ, Elliott JP, Winn HR, LeRoux PD. Relationship between intracranial pressure and other clinical variables in patients with aneurysmal subarachnoid hemorrhage. J Neurosurg. 2004;101(3): 408-416.

16. Rangel-Castillo L, Robertson CS. Management of intracranial hypertension. Crit Care Clin. 2006;22(4):713-732; abstract ix.

17. Stocchetti N, Zanaboni C, Colombo A, et al. Refractory intracranial hypertension and "second-tier" therapies in traumatic brain injury. Intensive Care Med. 2008;34(3):461-467.

18. Janjua N, Mayer SA. Cerebral vasospasm after subarachnoid hemorrhage. Curr Opin Crit Care. 2003;9(2):113-119.

19. Claassen J, Carhuapoma JR, Kreiter KT, Du EY, Connolly ES, Mayer SA. Global cerebral edema after subarachnoid hemorrhage: frequency, predictors, and impact on outcome. Stroke. 2002;33(5):1225-1232.

20. Rinkel GJ, Feigin VL, Algra A, van Gijn J. Circulatory volume expansion therapy for aneurysmal subarachnoid haemorrhage. Cochrane Database Syst Rev. 2004;(4):CD000483.

21. Lee KH, Lukovits T, Friedman JA. "Triple-H" therapy for cerebral vasospasm following subarachnoid hemorrhage. Neurocrit Care. 2006;4(1):68-76.

22. Schmidt JM, Rincon F, Fernandez A, et al. Cerebral infarction associated with acute subarachnoid hemorrhage. Neurocrit Care. 2007;7(1): $10-17$.

23. Nagel A, Graetz D, Schink T, et al. Relevance of intracranial hypertension for cerebral metabolism in aneurysmal subarachnoid hemorrhage. Clinical article. J Neurosurg. 2009;111(1):94-101.

24. Marmarou A, Anderson RL, Ward JD, et al. Impact of ICP instability and hypotension on outcome in patients with severe head trauma. J Neurosurg. 1991;75(1S):S59-S66.

25. Treggiari MM, Schutz N, Yanez ND, Romand JA. Role of intracranial pressure values and patterns in predicting outcome in traumatic brain injury: a systematic review. Neurocrit Care. 2007;6(2):104-112.

26. Nagel A, Graetz D, Vajkoczy P, Sarrafzadeh AS. Decompressive craniectomy in aneurysmal subarachnoid hemorrhage: relation to cerebral perfusion pressure and metabolism. Neurocrit Care. 2009;11(3): 384-394.

27. Gebel JM, Brott TG, Sila CA, et al. Decreased perihematomal edema in thrombolysis-related intracerebral hemorrhage compared with spontaneous intracerebral hemorrhage. Stroke. 2000;31(3): 596-600.

28. Ropper AH. Hyperosmolar therapy for raised intracranial pressure. N Engl J Med. 2012;367(8):746-752.

29. Bratton SL, Chestnut RM, Ghajar J, et al. Guidelines for the management of severe traumatic brain injury. II. Hyperosmolar therapy. J Neurotrauma. 2007;24 Suppl 1:S14-S20.

30. Thongrong C, Kong N, Govindarajan B, Allen D, Mendel E, Bergese SD. Current purpose and practice of hypertonic saline in neurosurgery: a review of the literature. World Neurosurg. Epub February 9, 2013.

31. Sarrafzadeh AS, Thomale UW, Haux D, Unterberg AW. Cerebral metabolism and intracranial hypertension in high grade aneurysmal subarachnoid haemorrhage patients. Acta Neurochir Suppl. 2005;95: 89-92.

32. Tseng MY, Al-Rawi PG, Pickard JD, Rasulo FA, Kirkpatrick PJ. Effect of hypertonic saline on cerebral blood flow in poor-grade patients with subarachnoid hemorrhage. Stroke. 2003;34(6):1389-1396.

33. Tseng MY, Al-Rawi PG, Czosnyka M, et al. Enhancement of cerebral blood flow using systemic hypertonic saline therapy improves outcome in patients with poor-grade spontaneous subarachnoid hemorrhage. J Neurosurg. 2007;107(2):274-282.

34. Suarez JI, Qureshi AI, Bhardwaj A, et al. Treatment of refractory intracranial hypertension with $23.4 \%$ saline. Crit Care Med. 1998;26(6): $1118-1122$.

35. Suarez JI, Qureshi AI, Parekh PD, et al. Administration of hypertonic (3\%) sodium chloride/acetate in hyponatremic patients with symptomatic vasospasm following subarachnoid hemorrhage. J Neurosurg Anesthesiol. 1999;11(3):178-184.
36. Bentsen G, Breivik H, Lundar T, Stubhaug A. Hypertonic saline (7.2\%) in $6 \%$ hydroxyethyl starch reduces intracranial pressure and improves hemodynamics in a placebo-controlled study involving stable patients with subarachnoid hemorrhage. Crit Care Med. 2006;34(12):2912-2917.

37. Al-Rawi PG, Tseng MY, Richards HK, et al. Hypertonic saline in patients with poor-grade subarachnoid hemorrhage improves cerebral blood flow, brain tissue oxygen, and pH. Stroke. 2010;41(1):122-128.

38. Zhao ZX, Wu C, He M. A systematic review of clinical outcomes, perioperative data and selective adverse events related to mild hypothermia in intracranial aneurysm surgery. Clin Neurol Neurosurg. 2012;114(7): $827-832$.

39. Sterz F, Zeiner A, Kurkciyan I, et al. Mild resuscitative hypothermia and outcome after cardiopulmonary resuscitation. J Neurosurg Anesthesiol. 1996;8(1):88-96.

40. Peterson K, Carson S, Carney N. Hypothermia treatment for traumatic brain injury: a systematic review and meta-analysis. $J$ Neurotrauma. 2008;25(1):62-71.

41. Bratton SL, Chestnut RM, Ghajar J, et al. Guidelines for the management of severe traumatic brain injury. III. Prophylactic hypothermia. J Neurotrauma. 2007;24 Suppl 1:S21-S25.

42. Piepgras A, Elste V, Frietsch T, Schmiedek P, Reith W, Schilling L. Effect of moderate hypothermia on experimental severe subarachnoid hemorrhage, as evaluated by apparent diffusion coefficient changes. Neurosurgery. 2001;48(5):1128-1134.

43. Li LR, You C, Chaudhary B. Intraoperative mild hypothermia for postoperative neurological deficits in intracranial aneurysm patients. Cochrane Database Syst Rev. 2012;2:CD008445.

44. Hindman BJ, Todd MM, Gelb AW, et al. Mild hypothermia as a protective therapy during intracranial aneurysm surgery: a randomized prospective pilot trial. Neurosurgery. 1999;44(1):23-32.

45. Todd MM, Hindman BJ, Clarke WR, Torner JC. Mild intraoperative hypothermia during surgery for intracranial aneurysm. $N$ Engl J Med. 2005;352(2):135-145.

46. Chouhan RS, Dash HH, Bithal PK, et al. Intraoperative mild hypothermia for brain protection during intracranial aneurysm surgery. J Anaesthesiol Clin Pharmacol. 2006;22(1):21-28.

47. Inamasu J, Ichikizaki K. Mild hypothermia in neurologic emergency: an update. Ann Emerg Med. 2002;40(2):220-230.

48. Seule MA, Muroi C, Mink S, Yonekawa Y, Keller E. Therapeutic hypothermia in patients with aneurysmal subarachnoid hemorrhage, refractory intracranial hypertension, or cerebral vasospasm. Neurosurgery. 2009;64(1):86-92; discussion 92-83.

49. Cordato DJ, Herkes GK, Mather LE, Morgan MK. Barbiturates for acute neurological and neurosurgical emergencies - do they still have a role? J Clin Neurosci. 2003;10(3):283-288.

50. Shapiro HM, Galindo A, Wyte SR, Harris AB. Rapid intraoperative reduction of intracranial pressure with thiopentone. Br J Anaesth. 1973;45(10):1057-1062.

51. Kassell NF, Peerless SJ, Drake CG, Boarini DJ, Adams HP. Treatment of ischemic deficits from cerebral vasospasm with high dose barbiturate therapy. Neurosurgery. 1980;7(6):593-597.

52. Finfer SR, Ferch R, Morgan MK. Barbiturate coma for severe, refractory vasospasm following subarachnoid haemorrhage. Intensive Care Med. 1999;25(4):406-409.

53. Perez-Barcena J, Llompart-Pou JA, Homar J, et al. Pentobarbital versus thiopental in the treatment of refractory intracranial hypertension in patients with traumatic brain injury: a randomized controlled trial. Crit Care. 2008;12(4):R112.

54. Roberts I, Sydenham E. Barbiturates for acute traumatic brain injury. Cochrane Database Syst Rev. 2012;12:CD000033.

55. Ward JD, Becker DP, Miller JD, et al. Failure of prophylactic barbiturate coma in the treatment of severe head injury. $J$ Neurosurg. 1985;62(3):383-388.

56. Eisenberg HM, Frankowski RF, Contant CF, Marshall LF, Walker MD. High-dose barbiturate control of elevated intracranial pressure in patients with severe head injury. J Neurosurg. 1988;69(1):15-23. 
57. Treggiari MM. Hemodynamic management of subarachnoid hemorrhage. Neurocrit Care. 2011;15(2):329-335.

58. Sahuquillo J, Arikan F. Decompressive craniectomy for the treatment of refractory high intracranial pressure in traumatic brain injury. Cochrane Database Syst Rev. 2006;(1):CD003983.

59. Whitfield P, Guazzo E. ICP reduction following decompressive craniectomy. Stroke. 1995;26(6):1125-1126.

60. Aarabi B, Hesdorffer DC, Ahn ES, Aresco C, Scalea TA, Eisenberg HM. Outcome following decompressive craniectomy for malignant swelling due to severe head injury. J Neurosurg. 2006;104(4):469-479.

61. Fisher CM, Ojemann RG. Bilateral decompressive craniectomy for worsening coma in acute subarachnoid hemorrhage. Observations in support of the procedure. Surg Neurol. 1994;41(1):65-74.

62. Jaeger M, Soehle M, Meixensberger J. Effects of decompressive craniectomy on brain tissue oxygen in patients with intracranial hypertension. J Neurol Neurosurg Psychiatry. 2003;74(4):513-515.

63. Stiefel MF, Heuer GG, Smith MJ, et al. Cerebral oxygenation following decompressive hemicraniectomy for the treatment of refractory intracranial hypertension. J Neurosurg. 2004;101(2):241-247.

64. Stuart RM, Claassen J, Schmidt M, et al. Multimodality neuromonitoring and decompressive hemicraniectomy after subarachnoid hemorrhage. Neurocrit Care. 2011;15(1):146-150.

65. Ohkuma H, Shimamura N, Fujita S, Suzuki S. Acute subdural hematoma caused by aneurysmal rupture: incidence and clinical features Cerebrovasc Dis. 2003;16(2):171-173.

66. Buschmann U, Yonekawa Y, Fortunati M, Cesnulis E, Keller E. Decompressive hemicraniectomy in patients with subarachnoid hemorrhage and intractable intracranial hypertension. Acta Neurochir (Wien). 2007;149(1):59-65.

67. Güresir E, Schuss P, Vatter H, Raabe A, Seifert V, Beck J. Decompressive craniectomy in subarachnoid hemorrhage. Neurosurg Focus. 2009;26(6):E4.
68. Schirmer CM, Hoit DA, Malek AM. Decompressive hemicraniectomy for the treatment of intractable intracranial hypertension after aneurysmal subarachnoid hemorrhage. Stroke. 2007;38(3):987-992.

69. Smith ER, Carter BS, Ogilvy CS. Proposed use of prophylactic decompressive craniectomy in poor-grade aneurysmal subarachnoid hemorrhage patients presenting with associated large sylvian hematomas. Neurosurgery. 2002;51(1):117-124.

70. Otani N, Takasato Y, Masaoka H, et al. Surgical outcome following decompressive craniectomy for poor-grade aneurysmal subarachnoid hemorrhage in patients with associated massive intracerebral or sylvian hematomas. Cerebrovasc Dis. 2008;26(6):612-617.

71. Stiver SI. Complications of decompressive craniectomy for traumatic brain injury. Neurosurg Focus. 2009;26(6):E7.

72. Mokri B. Orthostatic headaches in the syndrome of the trephined: resolution following cranioplasty. Headache. 2010;50(7):1206-1211.

73. Bijlenga P, Zumofen D, Yilmaz H, Creisson E, de Tribolet N. Orthostatic mesodiencephalic dysfunction after decompressive craniectomy. J Neurol Neurosurg Psychiatry. 2007;78(4):430-433.

74. Stiver SI, Wintermark M, Manley GT. Reversible monoparesis following decompressive hemicraniectomy for traumatic brain injury. J Neurosurg. 2008;109(2):245-254.

75. Polin RS, Shaffrey ME, Bogaev CA, et al. Decompressive bifrontal craniectomy in the treatment of severe refractory posttraumatic cerebral edema. Neurosurgery. 1997;41(1):84-92; discussion 92-84.

76. Waziri A, Fusco D, Mayer SA, McKhann GM 2nd, Connolly ES Jr. Postoperative hydrocephalus in patients undergoing decompressive hemicraniectomy for ischemic or hemorrhagic stroke. Neurosurgery. 2007;61(3):489-493; discussion 493-494.
Vascular Health and Risk Management

\section{Publish your work in this journal}

Vascular Health and Risk Management is an international, peerreviewed journal of therapeutics and risk management, focusing on concise rapid reporting of clinical studies on the processes involved in the maintenance of vascular health; the monitoring, prevention and treatment of vascular disease and its sequelae; and the involvement of

\section{Dovepress}

metabolic disorders, particularly diabetes. This journal is indexed on PubMed Central and MedLine. The manuscript management system is completely online and includes a very quick and fair peer-review system, which is all easy to use. Visit http://www.dovepress.com/ testimonials.php to read real quotes from published authors. 